\title{
EFECTOS DE UN MODELO DE ENTRENAMIENTO EN AUTOVALÍA SOBRE LA CONDUCTA RESILIENTE Y VIOLENTA DE ADOLESCENTES
}

\author{
Alberto Quintana P.' 1 , William Montgomery U., Elisa Yanac R., César Sarria J., Hilda Chávez Ch., Carmela \\ Malaver S. Jorge Soto M., Julio Alvites R., Edgar Herrera F., Leoncio Solórzano A. \\ Universidad Nacional Mayor de San Marcos, Perú
}

(Recibido el 13/11/2007, aceptado el 30/11/2007)

\begin{abstract}
RESUMEN
Se estudia la eficacia de un modelo de entrenamiento en autovalía para promover conductas resilientes y prevenir conductas violentas en un grupo de jóvenes (entre 14 y 16 años). Para ello se hicieron las coordinaciones con las instituciones educativas correspondientes que permitieron a los investigadores acceder a un grupo de 115 adolescentes del sexo femenino, a las cuales se les evaluó con instrumentos psicológicos estandarizados a fin de conocer el grado en que manifiestaban conductas resilientes y actitudes violentas. Luego se seleccionó al azar a 25 de ellas, a las cuales se les administró un taller de autovalía derivado de la terapia racional-emotiva de Albert Ellis, durante dos semanas. Finalizado el taller, se volvió a evaluar las conductas resilientes y actitudes violentas a las participantes del taller. Procediéndose a analizar los resultados con los estadísticos no paramétricos "Tau_b" de Kendall, "Rho" de Spearman y "Rangos con signo" de Wilconxon, con la ayuda del paquete estadístico SPSS versión 16. Obteniendo como resultado la comprobación de la hipótesis propuesta; es decir, el Taller de autovalía produce un desarrollo estadísticamente significativo de la conducta resiliente y una reducción, si bien de menor cuantía, también estadísticamente significativa, de las actitudes violentas en las jóvenes participantes.
\end{abstract}

Palabras clave: Jóvenes, Violencia, Resiliencia y Autovalía.

\begin{abstract}
We study the effectiveness of a model training autovalia to promote resiliente behaviors and prevent violent behavior in a group of young (between 14 and 16 years). This made the arrangements with educational institutions that allowed researchers access to a group of 115 adolescent girls, which were evaluated with standardized psychológical instruments in order to know the extent to which show resiliente behaviors and attitudes violent. Then was selected at random to 25 of them, which were given a workshop autovalia derived from the rational-emotive therapy of Albert Ellis, for two weeks. Endign the workshop, the resiliente behaviour and violent

1 Profesor principal, Facultad de Psicología UNMSM. E-mail: albertolope@yahoo.es.

Los autores agradecen la desinteresada colaboración de los alumnos: Aponte Accapari, Gabriela y Noe Retamozo, Jassin.
\end{abstract}


attitudes of workshop participants were assess. The results were analyzed with statisticians not Parameter "Tau_b" Kendall, "Rho" Spearman and "Ranges sign with" Wilconxon, with the help of SPSS 16. Getting as result in the testing of the hypothesis proposal, that is to say, that the qualification group of autovalia statistically produces a significant development of the resiliente conduct and a reduction, although of minor cuantia, also Statistically significant, of the violent attitudes in participant young.

Keywords: Young people, Violence, Resilience and Autovalia.

\section{INTRODUCCIÓN}

La juventud constituye uno de los estratos poblacionales más vulnerables en la actualidad. De acuerdo a las cifras ofrecidas por el Banco Mundial y las Naciones Unidas (Mangiaterra, McGinnis y Sánchez, 2003, 2005), en el mundo existen más de mil millones de jóvenes entre 15 y 24 años, entre los cuales las tasas de desempleo son dos o tres veces más altas que las de los adultos, casi la mitad de nuevas infecciones por VIH/SIDA corresponden a personas jóvenes, y por ejemplo, en América Latina sólo el $72 \%$ de los jóvenes logran acceder a la educación secundaria. En nuestro país los jóvenes representan el $28 \%$ de la población (Aramburú y Mendoza, 2003), de los cuales el 74\% reside en zonas urbanas, siendo de ellos el $60 \%$ migrantes.

La conducta violenta, agresiva, de los jóvenes, es uno de problemas de alta prevalencia en nuestro país. Según Ortiz (2005), actualmente, en el Perú existen 700 pandillas juveniles, de personas entre 13 y 24 años, que representan el $70 \%$ del total de la violencia. Según información del Ministerio Público (2001) sobre muertes violentas, en el área urbana, el $15.08 \%$ son causadas por homicidios.

"La agresividad es una característica de la naturaleza humana y ha sido fundamental para la evolución de la especie. Los comportamientos agresivos del hombre primitivo servían para la defensa de las hembras y las crías, la búsqueda de alimentos y la defensa del territorio. Es decir, estaban al servicio de la supervivencia. Sin embargo, a lo largo del tiempo, los comportamientos agresivos han modificado y ampliado este primer objetivo y han servido para que unos individuos sometan a otros, y para llevar a cabo la destrucción masiva del ser humano" (Mardomingo, 2002). La agresividad humana normal incluye comportamientos que poseen efectos negativos mínimos en el desarrollo psicológico de los adolescentes y/o en el entorno. Este comportamiento "normal" usualmente es temporal, transicional y a menudo condicional, su intensidad y frecuencia a menudo disminuyen como resultado de una intervención mínima o de ninguna intervención.

Pero la agresividad puede evolucionar hacia conductas antisociales. Cuando ello sucede se trata de una conducta antagonista, poco amistosa, asocial, hostil y alienadora. Suele comenzar en forma de negativismo y desafío. A menudo se halla en oposición directa a las normas, valores, escuela, comunidad, cultura o sociedad. Las formas más graves pueden resultar en la muerte de una persona o animal (Pratt y Greydanus, 2000)

La conducta violenta incluye aquellos actos realizados con la intención (o intención percibida) de causar daño físico a otra persona o que conducen a daño mental o físico a otros (incluyendo la muerte). Puede hablarse de un continuum entre agresividad y violencia 


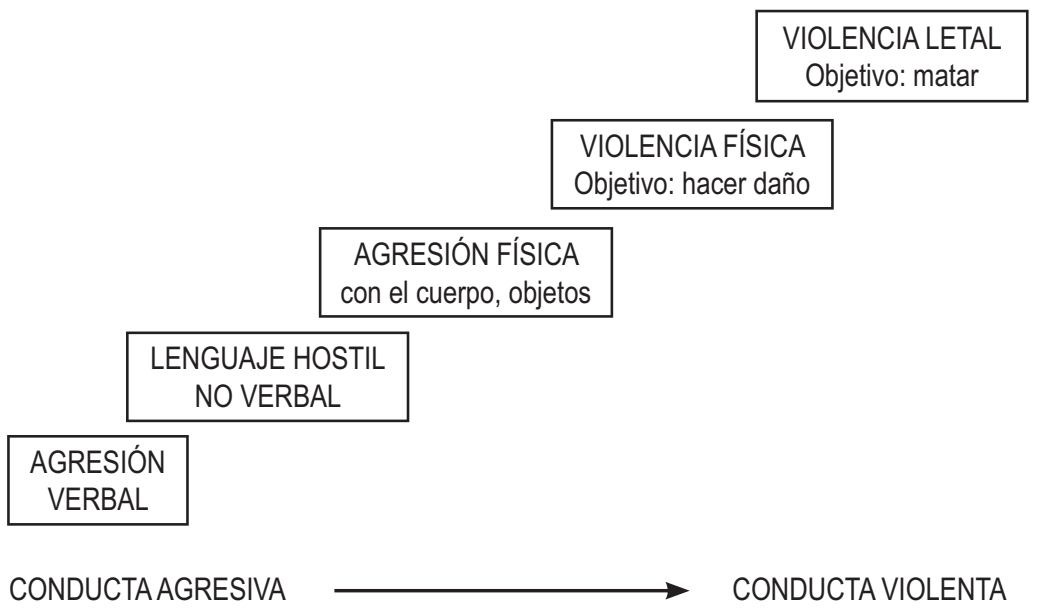

Fig. 1. Continuum entre agresividad y conducta violenta. Adaptado de Pratt y Greydanus (2000).

Es preocupación de los organismos gubernamentales los problemas que aquejan a la juventud. Así encontramos que en la Ley Nacional de la Juventud del Perú (Ley 27802), así como para los estudiosos de este tema (Martin y Reyes, 2003), la adolescencia como etapa de vida es también un asunto público fundamental para el desarrollo de las naciones. Por ello en el Perú, entre los lineamientos de política de organismos como el INABIF, PROMUDEH, MINDES y el Ministerio de Educación, se puede comprobar la existencia desde hace algunos años de programas para la prevención de la violencia.

Otros problemas sociales son los que sufren adolescentes que trabajan en desmedro de su desarrollo integral -sobre todo los que están expuestos a situaciones de alto riesgo- por ejemplo, los niños/as y adolescentes de la calle. Estos problemas sociales de los adolescentes se asocian a la pobreza y también al abandono familiar. En este contexto, un estudio de Anicama (1999) señala que uno de cada tres limeños maltrata psicológicamente a sus hijos $(36.2 \%)$ y dos de cada cuatro o cinco lo hace físicamente $(43.2 \%)$.

Frente a esta problemática, es pertinente recordar que es una de las funciones del encargo social de la psicología como profesión la construcción y validación de estrategias de intervención que prevengan conductas socialmente disfuncionales y que promuevan el desarrollo de conductas pro-sociales (Montgomery, 1998). Así se constata que en esta línea de trabajo, entre otros, Anicama y colaboradores $(1997,1999)$ han probado con cierto éxito programas para el desarrollo de habilidades sociales en alumnos con conductas agresivas.

En funcion de todo lo mencionado, es razonable concluir que la validación de estrategias en adolescentes que prevengan conductas violentas y/o promuevan la adquisición de conductas incompatibles con la violencia es un tema psicológico socialmente relevante.

En este empeño, durante los últimos años, en la psicología académica, son cada vez más abundantes las investigaciones centradas en el estudio de conductas disposicionales como 
la resiliencia, entendida como "los procesos sociales e intrapsíquicos que posibilitan tener una vida sana en un medio insano" (Rutter, 1993), o, dicho en otras paalabras, aquello que caracteriza a las personas que, a pesar de nacer y vivir en situaciones de alto riesgo ,se desarrollan psicológicamente sanas y exitosas (Citado por Rutter, 1993).

En la actualidad, la deducción más importante que se desprende de las investigaciones sobre resiliencia es la formación de personas socialmente competentes que tengan conciencia de su identidad, que puedan tomar decisiones, establecer metas y creer en un futuro mejor, satisfacer sus necesidades básicas de afecto, relación, respeto, metas, poder y significado, constituyéndose en personas productivas, felices y saludables.

Entre los estudios sobre resiliencia y autoestima es interesante destacar el trabajo del doctor Werner, (Walsh, 1998), quien hizo el seguimiento de 700 niños nacidos en la pobreza desde recién nacidos hasta los 40 años en la Isla de Kauai. Werner observó que resultaron resilientes aquellos que tuvieron por lo menos una persona, familiar o no, que los había aceptado como eran, en forma incondicional, independientemente de su temperamento, su aspecto físico o su inteligencia. Estos niños fueron creciendo con un alto nivel de autoestima al poder contar con alguien incondicional y al mismo tiempo sabiendo que sus esfuerzos eran reconocidos y fomentados.

Werner sostiene que todos los estudios realizados en el mundo acerca de niños muy sufridos, pero con autoestima alta, comprueban que esos niños tuvieron la influencia de por lo menos una relación cariñosa y estrecha con un adulto significativo. A partir de estas constataciónes, se identificó a la autoestima como la base de los demás factores que resultan protectores para los seres humanos, más allá de los efectos negativos de la adversidad (Walsh, 1998).

De ahí que cobra sentido el hecho de que durante los últimos años, en la psicología profesional, o aplicada, se observe, dentro de una estrategia más que nada preventivopromocional, la proliferación de talleres para el desarrollo de la asertividad y la autoestima (Montgomery, 1999).

Sin embargo, resulta necesario reflexionar que para Branden (1994, p 45), uno de los estudiosos más representativos de este tema, "La autoestima es la predisposición a experimentarse como competente para afrontar los desafíos de la vida y como merecedor de felicidad". Esto implica, si se analiza detenidamente que, aun cuando la persona tenga de sí misma una alta estima, estará enganchada en el proceso de evaluar su valía total, basándose en algunas características personales o en el afecto ofrecido por otro, es decir, estaría utilizando la falacia de afirmar para todos sus actos aquello que solamente habría comprobado para algunos de ellos, o bien, estaría subordinando sus propios estándares de estimación del valor personal a los estándares de los demás.

En consecuencia, para mantener dicha estima, la persona debería continuar demostrando sus características de valía y esforzarse por mantener el afecto de los demás; un estado de cosas a no dudarlo altamente ansiógeno, es decir amenazante; puesto que si fracasa en esta tarea perdería su tenue dominio sobre su autoestima. Por otro lado, se puede afirmar que incluso aquellas personas que están, podría decirse, "bendecidas" con muchas de las características que asociamos con la valoración personal, no necesariamente serían 
personas mentalmente saludables, pues en ocasiones esta situacion en sí misma les crea un problema; en tanto podría llevarlas a ser egoístas, soberbias y narcisistas. Estado en el cual, genuina, aunque neuróticamente, creerian que tienen más valor que otros y actuarían, según esta creencia, de maneras interesadas y auto-centradas. Para, posteriormente, cuando sus criterios para el engrandecimiento cesen, como definitivamente suele suceder, ver desvanecida su grandiosidad y experimentar rápidamente una merma en su autoestima.

En contraste a Branden (1994, p 45), ya Ellis, en 1981, reflexionaba: "... En vez de valorar excesivamente su YO y el de los demás, las personas pueden limitarse a valorar solamente sus ACTUACIONES...", es decir, en tanto somos demasiado multifacéticos para ser clasificados o evaluados a partir de un pequeño grupo de rasgos o conductas como una entidad total, resultaría pertinente, más que fomentar la autoestima, fomentar la autoaceptación.

En la terapia racional-emotiva de Albert Ellis, la autoaceptación es un concepto, cuyo significado se refiere al hecho de que el individuo se acepta total e incondicionalmente, se comporte de manera inteligente, correcta, competentemente, o no. Por lo tanto, mientras que sólo los individuos que se comportan bien pueden merecer y sentir autoestima, virtualmente todos los humanos son capaces de sentir autoaceptación. La alternativa más concreta es que la gente aprenda a reconocer su extrema complejidad, sabiendo que un intento de evaluarse es científicamente condenable, y reconocer que no tiene una valía extrínseca, sino un valor por el sentido de estar viva y que potencialmente puede ser feliz y estar contenta con lo que hace sin tener que evaluarse; y es que la gente puede y desde luego "debería evaluar sus rasgos", porque esto le facilitará la planificacion de las estrategias más adecuadas para el logro de sus metas de vida y el control de las mismas; pero además puede aceptarse totalmente a sí misma no importando los rasgos útiles o perjudiciales que descubra. El entrenamiento en autovalía en la perspectiva de la terarapia racional emotiva es una manera eficaz de fomentar la autoaceptación.

A partir de estas reflexiones, resulta plausible afirmar que frente a la pregunta: ¿Qué efectos tendrá un Modelo de Entrenamiento en Autovalía sobre la Conducta Resilente y Actitudes Violentas de los Adolescentes?

Las respuestas más plausibles serían:

H1 El grupo de jóvenes que participa en el taller de autovalía manifestará un mayor grado de conducta resiliente después del taller que el que presentaba antes del taller.

H2 El grupo de jóvenes que participa en el taller de autovalía manifestará un menor grado de conducta violenta despues del taller que el que presentaba antes del taller.

\section{MÉTODO}

El presente estudio es de carácter experimental, pero no básico (explicativo) sino tecnológico (trata de probar la eficacia de un modelo de intervención). Su diseño de investigación, tratándose de una variable independiente manipulada, es de grupo aleatorio "antes y después", sin grupo de control (Alarcón, 1991). 
La muestra inicialmente estuvo conformada por 25 adolescentes de la ciudad de Lima, seleccionadas al azar como integrantes del grupo experimental, pero, por muertes experimentales ajenas al control de los investigadores, se redujo a 22 alumnas, quienes respondieron consistente y validamente a las tareas previstas en el Taller y a los instrumentos administrados para evaluar la resiliencia y las actitudes violentas.

\section{Variables}

Variable independiente: Taller de entrenamiento en autovalía para adolescentes

Variable dependiente $\quad 1$. Conducta resiliente

Variable dependiente 2. Actitudes violentas

Variables controladas:

$\begin{array}{ll}\text { Nivel socioeconómico } & \text { (medio) } \\ \text { Edad } & (15-24 \text { años }) \\ \text { Instrucción } & \text { (secundaria) } \\ \text { Sexo } & \text { (femenino) } \\ \text { Área geográfica } & \text { (Lima metropolitana). }\end{array}$

\section{Instrumentos}

Ficha demográfica: Permite registrar algunas características relevantes de los sujetos estudiados: Lugar de residencia, edad, sexo, grado de instrucción, etc.

Escala de resiliencia: Elaborada por Wagnild \& Young, con el objetivo de estimar el grado de resiliencia. Ella consta de veinticinco ítems. Calificados de 1 a 7 , en función del grado de acuerdo o desacuerdo con cada afirmacion. Está compuesta de dos factores: Competencia personal (17 ítems) y Aceptación de sí mismo y de su vida (8 ítems). Todos los ítems se basan en una escala de 7 puntos; a partir del 1 "Estar en desacuerdo", hasta el 7 "Estar de acuerdo". Todos los ítems están escritos en forma positiva y reflejan con exactitud las declaraciones hechas por los participantes. Los posibles resultados varían desde 25 hasta 175 en donde, a mayor puntaje, se considera que existe mayor resiliencia (Citado por Del Águila, 2003). Salgado (2005) refiere una adaptación de esta prueba que da lugar a la estimación de cinco características de la resiliencia, a saber:

"Confianza en sí mismo", es la creencia en uno mismo y en sus propias capacidades; también es considerada como la habilidad de depender de uno mismo y reconocer sus propias fuerzas y limitaciones.

"Ecuanimidad", considerada como la perspectiva balanceada de su propia vida y experiencias; connota la habilidad de considerar un amplio campo de experiencia y "esperar tranquilo' y, tomar las cosas como vengan; por ende, se moderan las respuestas extremas ante la adversidad. 
"Perseverancia", está referida al acto de persistencia a pesar de la adversidad o desaliento; la perseverancia connota un fuerte deseo de continuar luchando para construir la vida de uno mismo, permanecer involucrado y de practicar la autodisciplina.

"Satisfacción personal”, está referida al comprender que la vida tiene un significado y evaluar las propias contribuciones.

Y "Sentirse bien solo", referida a la comprensión de que la senda de vida de cada persona es única mientras que se comparten algunas experiencias; quedan otras que deben enfrentarse solo, el sentirse bien solo nos da un sentido de libertad y un significado de ser únicos.

Escala IMECH: Elaborada por Spilberg con el objetivo de obtener una evaluación de la conducta irritable, agresiva o violenta, esta compuesta de dos subescalas: Irritabilidad de estado (10 ítems) y de rasgo (10 ítems). La escala de estado se califica de 1 a 4 , en función del grado de acuerdo o desacuerdo con cada afirmación y la escala de rasgo se califica de 1 a 4, en función a la frecuencia con la que el sujeto experimenta el ítem, para la presente investigación se ha utilizado solo la escala de rasgo; entendida como un indicador de la probabilidad de ocurrencia de la autoobservación a la que se refiere el ítem en cuestión.

\section{Técnica para aplicar la variable independiente}

Taller de Valía personal y Autoaceptación: Desarrollado en la perspectiva conceptual de la Terapia Racional-emotiva de Albert Ellis, tiene como objetivo primordial la reestructuración cognitiva del concepto de valía personal implicada en el concepto de Autoestima y proponiendo la aceptación implícita de la valía del ser humano no sujeta a comprobación por el logro de metas o desarrollo de aptitudes internas o externas. Plantea además la autoaceptación como forma objetiva de recoger la realidad individual, para luego, sin presiones ni condicionamientos internos, encaminar los esfuerzos a las metas de cambio que cada individuo autopropone; revalorizando y distinguiendo de esta manera la voluntad como principal elemento motivador del desarrollo personal.

- Objetivo general del Taller:

Posibilitar que los participantes logren una adecuada y constructiva autoaceptación y valoración personal.

- Objetivos específicos del Taller:

Al terminar el taller el participante:

- Reconocerá el tipo de concepto que maneja sobre valía personal,

- Logrará diferenciar el valor intrínseco de la persona del valor condicionado a logros internos o externos o comportamientos socialmente aceptados,

- Expresará cómo percibe y aceptará cómo es percibido por sus compañeros,

- Reformulará su concepto de valía personal. 
- Metodología:

Modificación de autoverbalizaciones y reestructuración de creencias en tres sesiones de 110 minutos cada una.

- Sesiones:

Sesión 1: Reconociendo mi modo de valorarme

Objetivos: Al terminar esta sesión el participante:

1. Identificará cualidades, virtudes, limitaciones y desvirtudes de las personas a las cuales califica como valiosas y poco valiosas

2. Identificará las situaciones en las que él se percibió como valioso/a y poco valioso/a, así como las características determinantes.

3. Definirá las características que el grupo define como cualidades de una persona valiosa.

4. Reconocerá el tipo de concepto que maneja sobre valía personal.

5. Logrará conocer por nombre, preferencias culinarias y talla del calzado a sus compañeros de grupo.

Metodología de la sesión:

- Exposición

- Dinámica de llenado del formato de trabajo

- Dinámica de animación

- Dinámica de lluvia de ideas por tarjetas

Sesión 2: Diferenciando conceptos de valía personal.

Objetivos: Al terminar esta sesión el participante:

1. Identificará los adjetivos o comportamientos aceptados que se encuentran en su definición de valía.

2. Logrará diferenciar el valor intrínseco de la persona del valor condicionado a logros internos o externos o comportamientos socialmente aceptados.

3. Cuestionará la definición de valía basada en logros internos o externos o comportamientos socialmente aceptados.

4. Reformulará el concepto de valía personal.

5. Fortalecerá sus vínculos con los otros miembros del grupo.

Metodología de la sesión:

- Exposición

- Dinámica de llenado del formato

- Dinámica de participación 
- Dinámica de lectura

- Dinámica de lluvia de ideas

Sesión 3: Viviendo el nuevo concepto de valía personal

Objetivos: Al terminar esta sesión el participante:

1. Recordará las sesiones anteriores.

2. Aceptará y reconocerá algunos de sus rasgos positivos y negativos.

3. Expresará cómo percibe y aceptará cómo es percibido por sus compañeros.

4. Se comprometerá a trabajar en revertir una de sus desvirtudes.

5. Reflexionará sobre la influencia del concepto errado de valía al problema del consumo de drogas.

6. Fortalecerá sus vínculos con los otros miembros del grupo.

Metodología de la sesión:

- Dinámica de participación

- Dinámica de reflexión

- Dinamita de plenario

- Dinámica de despedida y cierre

\section{Procedimiento}

1. Establecer las coordinaciones necesarias para acceder a la muestra y administrarle los instrumentos de medición y el taller de entrenamiento en autovalía.

2. Efectuar un muestreo de la población, extrayendo al azar las 25 adolescentes a investigar.

3. Recoger la información acerca de la conducta resiliente y las actitudes violentas de los adolescentes antes de administrar el taller.

4. Gestionar el Taller de autovalía.

5. Volver a evaluar las conductas resilientes y violentas en ambos grupos de adolescentes, los participantes del taller y los que no han participado.

6. Analizar los resultados con los estadísticos no paramétricos "Tau_b" de Kendall, "Rho" de Spearman y "Rangos con signo" de Wilconxon, con la ayuda del paquete estadístico SPSS versión 16.

\section{RESULTADOS Y DISCUSIÓN}

Se comprobó la hipótesis H1 "El grupo de jóvenes que participa en el taller de autovalía manifestará un menor grado (estadísticamente significativo menor al 0.05) de actitudes violentas después del taller que el que presentaba antes del taller", como se observa en las Figuras 1 y 3 y la Tabla 1. 
Figura 1. Actitudes violentas antes y después del Taller de autovalía.

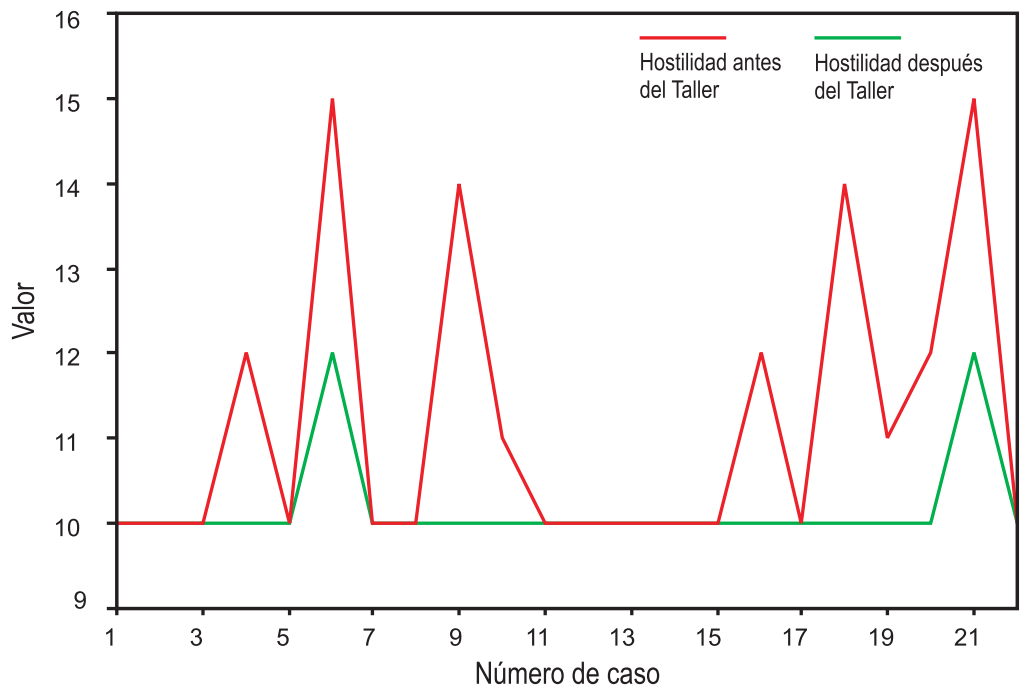

Tabla 1. Correlaciones no paramétricas.

\begin{tabular}{|c|c|c|c|c|}
\hline \multirow[t]{11}{*}{$\begin{array}{l}\text { Hostilidad } \\
\text { antes del } \\
\text { Taller }\end{array}$} & $\begin{array}{l}\text { Tau_b de } \\
\text { Kendall }\end{array}$ & $\begin{array}{l}\text { Coeficiente } \\
\text { de correlación }\end{array}$ & $\begin{array}{l}\text { Hostilidad } \\
\text { antes del } \\
\text { Taller } \\
\text { Hostilidad } \\
\text { después } \\
\text { del Taller }\end{array}$ & $\begin{array}{l}1.000 \\
.522^{*}\end{array}$ \\
\hline & & $\begin{array}{l}\text { Sig. } \\
\text { (bilateral) }\end{array}$ & $\begin{array}{l}\text { Hostilidad } \\
\text { antes del } \\
\text { Taller }\end{array}$ & \\
\hline & & & $\begin{array}{l}\text { Hostilidad } \\
\text { después } \\
\text { del Taller }\end{array}$ & .010 \\
\hline & & $\mathrm{N}$ & $\begin{array}{l}\text { Hostilidad } \\
\text { antes del } \\
\text { Taller }\end{array}$ & 22 \\
\hline & & & $\begin{array}{l}\text { Hostilidad } \\
\text { después } \\
\text { del Taller }\end{array}$ & 22 \\
\hline & $\begin{array}{l}\text { Rho de } \\
\text { Spearman }\end{array}$ & $\begin{array}{l}\text { Coeficiente } \\
\text { de correlación }\end{array}$ & $\begin{array}{l}\text { Hostilidad } \\
\text { antes del } \\
\text { Taller }\end{array}$ & 1.000 \\
\hline & & & $\begin{array}{l}\text { Hostilidad } \\
\text { después } \\
\text { del Taller }\end{array}$ & $.561^{* *}$ \\
\hline & & $\begin{array}{l}\text { Sig. } \\
\text { (bilateral) }\end{array}$ & $\begin{array}{l}\text { Hostilidad } \\
\text { antes del } \\
\text { Taller }\end{array}$ & \\
\hline & & & $\begin{array}{l}\text { Hostilidad } \\
\text { después } \\
\text { del Taller }\end{array}$ & .007 \\
\hline & & $\mathrm{N}$ & $\begin{array}{l}\text { Hostilidad } \\
\text { antes del } \\
\text { Taller }\end{array}$ & 22 \\
\hline & & & $\begin{array}{l}\text { Hostilidad } \\
\text { después } \\
\text { del Taller }\end{array}$ & 22 \\
\hline
\end{tabular}

* La correlación es significativa al nivel 0.05 (bilateral)

** La correlación es significativa al nivel 0.01 (bilateral) 
Figura 2. Diferencia en las actitudes violentas antes y después del Taller de autovalía.

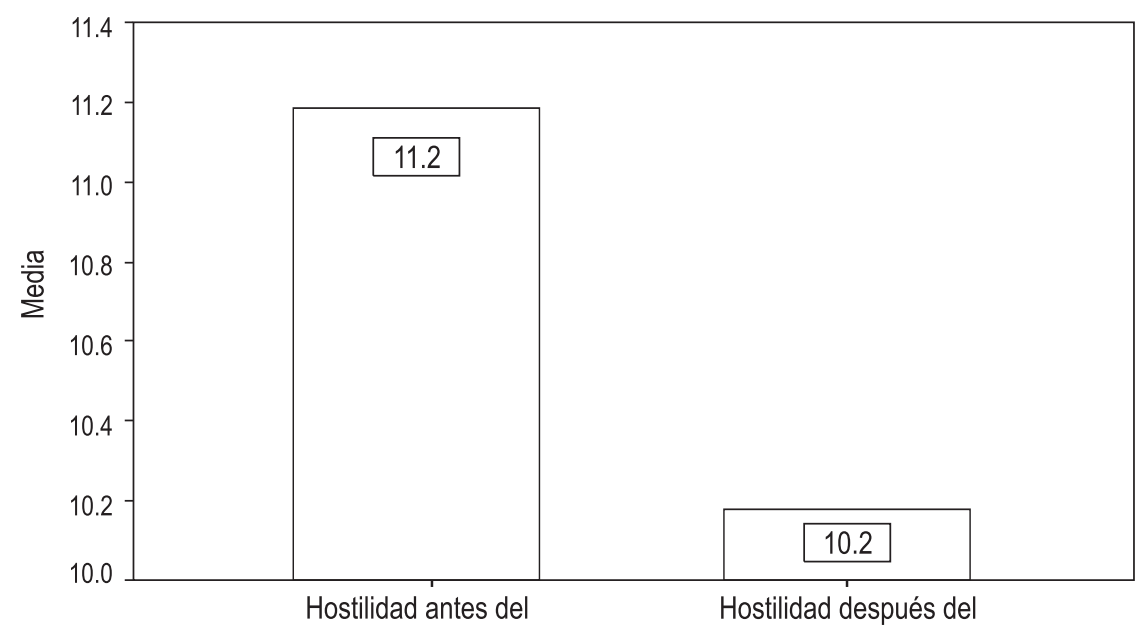

Se comprobó la hipótesis H2 "El grupo de jóvenes que participa en el taller de autovalía manifestará un mayor grado (estadísticamente significativo al 0.01) de conducta resiliente después del taller que el que presentaba antes del taller", como se observa en las Figuras 2 y 4 y la Tabla 2 .

Figura 3. Actitudes resilientes antes y después del Taller de autovalía.

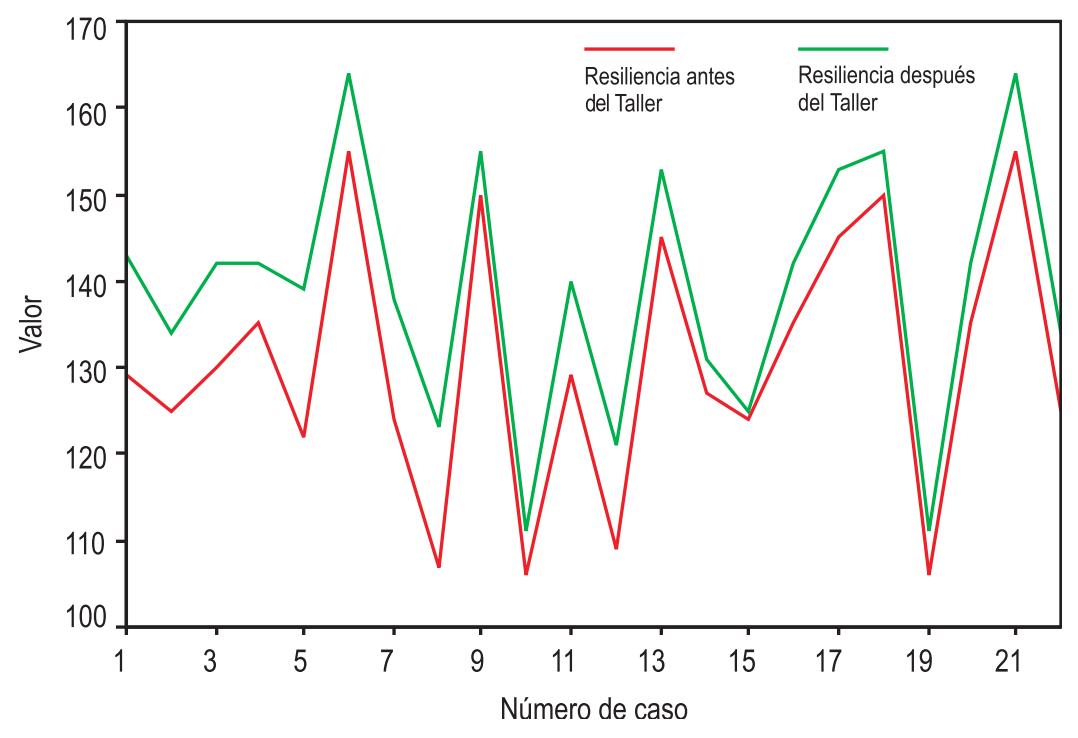


Tabla 2. Correlaciones No paramétricas.

\begin{tabular}{|c|c|c|c|c|}
\hline & & & $\begin{array}{c}\text { Resiliencia } \\
\text { antes del } \\
\text { Taller }\end{array}$ & $\begin{array}{c}\text { Resiliencia } \\
\text { después } \\
\text { del Taller }\end{array}$ \\
\hline \multirow[t]{2}{*}{$\begin{array}{l}\text { Tau_b de } \\
\text { Kendall }\end{array}$} & $\begin{array}{l}\text { Coeficiente } \\
\text { de } \\
\text { correlación }\end{array}$ & $\begin{array}{l}\text { Resiliencia } \\
\text { antes del } \\
\text { Taller }\end{array}$ & 1.000 & $.853^{* *}$ \\
\hline & & $\begin{array}{l}\text { Resiliencia } \\
\text { después } \\
\text { del Taller }\end{array}$ & $.853^{* *}$ & 1.000 \\
\hline \multirow[t]{2}{*}{$\begin{array}{l}\text { Rho de } \\
\text { Spearman }\end{array}$} & $\begin{array}{l}\text { Coeficiente } \\
\text { de } \\
\text { correlación }\end{array}$ & $\begin{array}{l}\text { Resiliencia } \\
\text { antes del } \\
\text { Taller }\end{array}$ & 1.000 & $.954^{* *}$ \\
\hline & & $\begin{array}{l}\text { Resiliencia } \\
\text { después } \\
\text { del Taller }\end{array}$ & .954 ** & 1.000 \\
\hline
\end{tabular}

** La correlación es significativa al nivel 0,01 (bilateral).

Figura 4. Diferencia en el nivel de resilencia antes y después del Taller de autovalía.

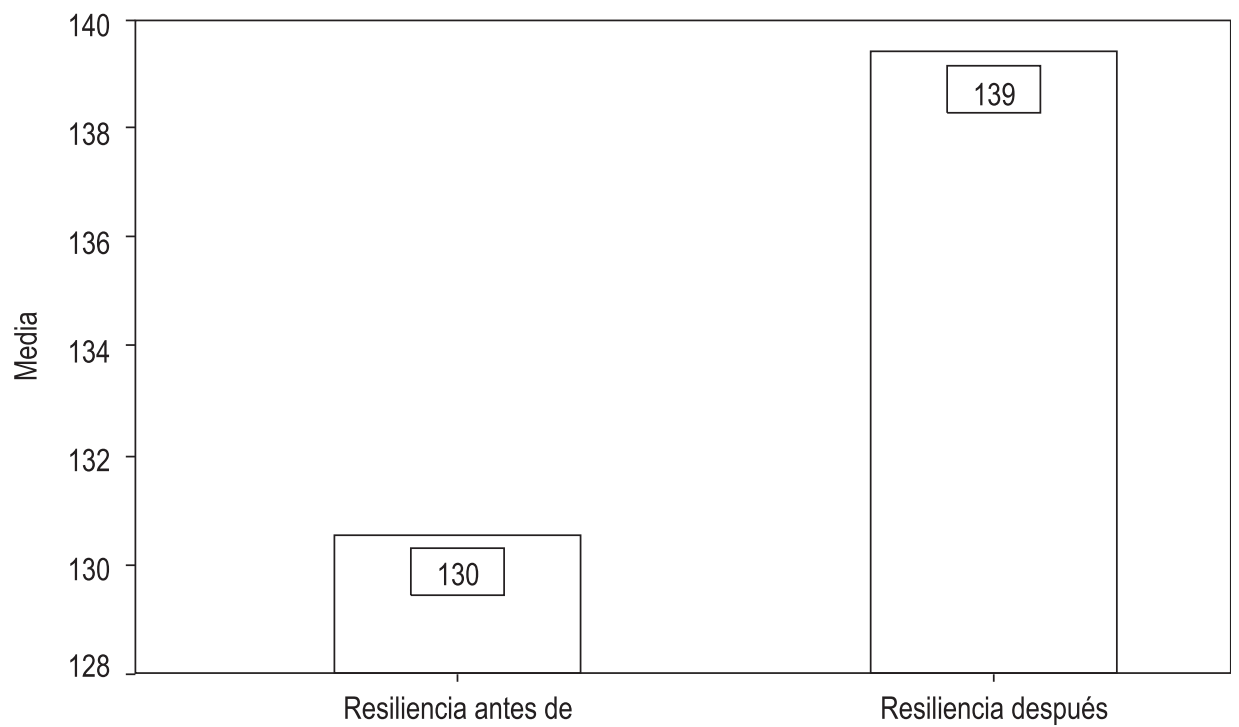

Dócima de hipótesis que comprueba que las diferencias observadas en las figuras son estadísticamente significativas: 
Tabla 3. Prueba de los rangos con signo de Wilconxon.

\begin{tabular}{llccc}
\hline & $\mathrm{N}$ & $\begin{array}{c}\text { Rango } \\
\text { promedio }\end{array}$ & $\begin{array}{c}\text { Suma de } \\
\text { rangos }\end{array}$ \\
\hline $\begin{array}{l}\text { Hostilidad } \\
\text { después }\end{array}$ & $\begin{array}{l}\text { Rangos } \\
\text { negativos }\end{array}$ & $9^{\mathrm{a}}$ & 5.00 & 45.00 \\
del Taller- & Rangos & & & \\
Hostilidad & positivos & $0^{\mathrm{b}}$ & .00 & .00 \\
antes del & Empates & $13^{\mathrm{c}}$ & & \\
Taller & Total & 22 & & \\
\hline
\end{tabular}

a. Hostilidad después del Taller < Hostilidad antes del Taller

b. Hostilidad después del Taller > Hostilidad antes del Taller

c. Hostilidad antes del Taller $=$ Hostilidad después del Taller

Estadísticos de contraste b

\begin{tabular}{|c|c|}
\hline & $\begin{array}{l}\text { Hostilidad después del Taller } \\
- \\
\text { Hostilidad antes del Taller }\end{array}$ \\
\hline Z & $-2.682^{a}$ \\
\hline $\begin{array}{l}\text { Sig. } \\
\text { asintót. } \\
\text { (bilateral) }\end{array}$ & .007 \\
\hline
\end{tabular}

a. Basado en los rangos positivos

b. Prueba de los rangos con signo de Wilcoxon.

Tabla 4. Prueba de los signos.

\begin{tabular}{|c|c|c|c|}
\hline & Frecuencias & & $\mathrm{N}$ \\
\hline $\begin{array}{l}\text { Hostilidad } \\
\text { después }\end{array}$ & $\begin{array}{l}\text { Diferencias } \\
\text { negativas }\end{array}$ & a & 9 \\
\hline $\begin{array}{l}\text { del Taller - } \\
\text { Hostilidad }\end{array}$ & $\begin{array}{l}\text { Diferencias } \\
\text { positivas }\end{array}$ & $b$ & 0 \\
\hline \multirow{2}{*}{$\begin{array}{l}\text { antes del } \\
\text { Taller }\end{array}$} & Empates & C & 13 \\
\hline & Total & & 22 \\
\hline
\end{tabular}

a. Hostilidad después del Taller < Hostilidad antes del Taller

b. Hostilidad después del Taller $>$ Hostilidad antes del Taller

c. Hostilidad antes del Taller $=$ Hostilidad después del Taller 
Estadísticos de contraste b

\begin{tabular}{lc}
\hline & $\begin{array}{c}\text { Hostilidad } \\
\text { después } \\
\text { del Taller } \\
\\
\end{array}$ \\
& - \\
& Hostilidad \\
& antes del \\
& Taller \\
\hline Sig. & \\
exacta & $.004^{\text {a }}$ \\
(bilateral) & \\
\hline
\end{tabular}

a. Se ha usado la distribución binomial.

b. Prueba de los signos.

Tabla 5. Prueba de los rangos con signo de Wilcoxon.

\begin{tabular}{llccr}
\hline & $\mathrm{N}$ & $\begin{array}{c}\text { Rango } \\
\text { promedio }\end{array}$ & $\begin{array}{c}\text { Suma de } \\
\text { rangos }\end{array}$ \\
\hline $\begin{array}{l}\text { Resiliencia } \\
\text { después } \\
\text { del Taller- }\end{array}$ & $\begin{array}{l}\text { Rangos } \\
\text { negativos }\end{array}$ & $0^{\mathrm{a}}$ & .00 & .00 \\
$\begin{array}{l}\text { Resiliencia } \\
\text { antes del }\end{array}$ & $\begin{array}{l}\text { Rangos } \\
\text { positivos }\end{array}$ & $22^{\mathrm{b}}$ & 11.50 & 253.00 \\
Taller & Empates & $0^{\mathrm{c}}$ & & \\
\hline
\end{tabular}

a. Resiliencia después del Taller < Resiliencia antes del Taller

b. Resiliencia después del Taller $>$ Resiliencia antes del Taller

c. Resiliencia antes del Taller $=$ Resiliencia después del Taller

Estadísticos de contraste $b$

\begin{tabular}{lc}
\hline & $\begin{array}{c}\text { Resiliencia } \\
\text { después del Taller- } \\
\text { Resiliencia } \\
\text { antes del Taller }\end{array}$ \\
\hline$Z$ & $-4.114^{\mathrm{a}}$ \\
$\begin{array}{l}\text { Sig. } \\
\text { asintót. } \\
\text { (bilateral) }\end{array}$ & .000 \\
\hline
\end{tabular}

a. Basado en los Rangos negativos.

b. Prueba de los rangos con signo de Wilcoxon. 
Tabla 6. Prueba de los signos.

\begin{tabular}{|c|c|c|c|}
\hline & Frecuencias & & $\mathrm{N}$ \\
\hline \multirow{4}{*}{$\begin{array}{l}\text { Resiliencia } \\
\text { después } \\
\text { del Taller- } \\
\text { Resiliencia } \\
\text { antes del } \\
\text { Taller }\end{array}$} & $\begin{array}{l}\text { Diferencias } \\
\text { negativas }\end{array}$ & a & \\
\hline & $\begin{array}{l}\text { Diferencias } \\
\text { positivas }\end{array}$ & $b$ & 22 \\
\hline & Empates & c & 0 \\
\hline & Total & & 22 \\
\hline
\end{tabular}

a. Resiliencia después del Taller < Resiliencia antes del Taller.

b. Resiliencia después del Taller $>$ Resiliencia antes del Taller.

c. Resiliencia antes del Taller = Resiliencia después del Taller.

\section{Estadísticos de contraste b}

\begin{tabular}{lc}
\hline & $\begin{array}{c}\text { Resiliensia } \\
\text { después } \\
\text { del Taller - } \\
\text { Resiliensia } \\
\text { antes del } \\
\text { Taller }\end{array}$ \\
\hline $\begin{array}{l}\text { Sig. } \\
\text { exacta } \\
\text { (bilateral) }\end{array}$ & $.000^{\mathrm{a}}$ \\
\hline
\end{tabular}

a. Se ha usado la distribución binomial.

b. Prueba de los signos.

Tabla 7. Correlaciones no paramétricas.

\begin{tabular}{|c|c|c|c|c|c|}
\hline & & & $\begin{array}{c}\text { Resiliencia } \\
\text { antes del } \\
\text { Taller }\end{array}$ & $\begin{array}{c}\text { Confianza } \\
\text { en sí mismo } \\
\text { antes del } \\
\text { Taller }\end{array}$ & $\begin{array}{c}\text { Ecuanimidad } \\
\text { antes del } \\
\text { Taller }\end{array}$ \\
\hline \multirow{6}{*}{$\begin{array}{l}\text { Coeficiente } \\
\text { de } \\
\text { correlación }\end{array}$} & \multirow{2}{*}{$\begin{array}{l}\text { Resiliencia } \\
\text { antes del } \\
\text { Taller }\end{array}$} & $\begin{array}{l}\text { Tau_b de } \\
\text { Kendall }\end{array}$ & 1.000 & $.797^{* *}$ & .266 \\
\hline & & $\begin{array}{l}\text { Rho de } \\
\text { Spearman }\end{array}$ & 1.000 & $.919^{* *}$ & .286 \\
\hline & \multirow{2}{*}{$\begin{array}{l}\text { Confianza en } \\
\text { sí mismo } \\
\text { antes del } \\
\text { Taller }\end{array}$} & $\begin{array}{l}\text { Tau_b de } \\
\text { Kendall }\end{array}$ & $.797^{\star *}$ & 1.000 & .078 \\
\hline & & $\begin{array}{l}\text { Rho de } \\
\text { Spearman }\end{array}$ & $.919^{* *}$ & 1.000 & .069 \\
\hline & \multirow{2}{*}{$\begin{array}{l}\text { Ecuanimidad } \\
\text { antes del } \\
\text { Taller }\end{array}$} & $\begin{array}{l}\text { Tau_b de } \\
\text { Kendall }\end{array}$ & .266 & .078 & 1.000 \\
\hline & & $\begin{array}{l}\text { Rho de } \\
\text { Spearman }\end{array}$ & .286 & .069 & 1.000 \\
\hline
\end{tabular}

**a correlación es significativa al nivel 0,01 (bilateral). 


\begin{tabular}{|c|c|c|c|c|c|c|}
\hline & & & $\begin{array}{c}\text { Resiliencia } \\
\text { antes del } \\
\text { Taller }\end{array}$ & $\begin{array}{c}\text { Satisfacción } \\
\text { personal } \\
\text { antes del } \\
\text { Taller }\end{array}$ & $\begin{array}{c}\text { Perseverancia } \\
\text { antes del } \\
\text { Taller }\end{array}$ & $\begin{array}{c}\text { Sentirse } \\
\text { bien solo } \\
\text { antes de } \\
\text { Taller }\end{array}$ \\
\hline \multirow{8}{*}{$\begin{array}{l}\text { Coeficiente } \\
\text { de } \\
\text { correlación }\end{array}$} & \multirow{2}{*}{$\begin{array}{l}\text { Resiliencia } \\
\text { antes del } \\
\text { Taller }\end{array}$} & $\begin{array}{l}\text { Tau_b de } \\
\text { Kendall }\end{array}$ & 1.000 & $.448^{* *}$ & .601 ** & $.666^{* *}$ \\
\hline & & $\begin{array}{l}\text { Rho de } \\
\text { Spearman }\end{array}$ & 1.000 & $.621^{* *}$ & $.748^{* *}$ & $.820^{* *}$ \\
\hline & \multirow{2}{*}{$\begin{array}{l}\text { Satisfacción } \\
\text { personal } \\
\text { antes del } \\
\text { Taller }\end{array}$} & $\begin{array}{l}\text { Tau_b de } \\
\text { Kendall }\end{array}$ & $.448^{* *}$ & 1.000 & .113 & $.449^{* *}$ \\
\hline & & $\begin{array}{l}\text { Rho de } \\
\text { Spearman }\end{array}$ & .621 ** & 1.000 & .144 & $.621^{\star *}$ \\
\hline & \multirow{2}{*}{$\begin{array}{l}\text { Perseverancia } \\
\text { antes del } \\
\text { Taller }\end{array}$} & $\begin{array}{l}\text { Tau_b de } \\
\text { Kendall }\end{array}$ & $.601 * *$ & .113 & 1.000 & $.485^{* *}$ \\
\hline & & $\begin{array}{l}\text { Rho de } \\
\text { Spearman }\end{array}$ & $.748^{* *}$ & .144 & 1.000 & $.618^{* *}$ \\
\hline & \multirow{2}{*}{$\begin{array}{l}\text { Sentirse bien } \\
\text { solo antes del } \\
\text { Taller }\end{array}$} & $\begin{array}{l}\text { Tau_b de } \\
\text { Kendall }\end{array}$ & $.666^{* *}$ & .449 ** & $.485^{* *}$ & 1.000 \\
\hline & & $\begin{array}{l}\text { Rho de } \\
\text { Spearman }\end{array}$ & .820 ** & .621 ** & $.618^{* *}$ & 1.000 \\
\hline
\end{tabular}

**La correlación es significativa al nivel 0,01 (bilateral).

Figura 5. Correlación de la resiliencia y componentes antes del Taller de autovalía.

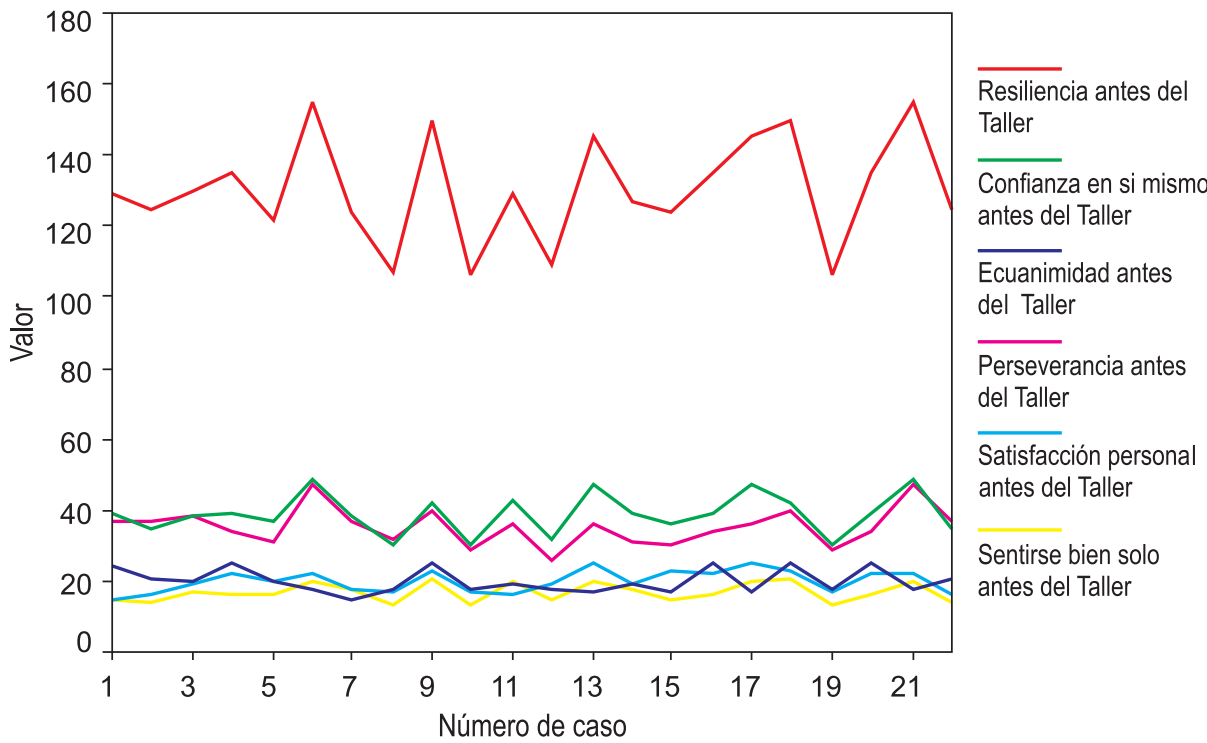


Figura 6. Correlación de la resiliencia y sus componentes después del Taller.

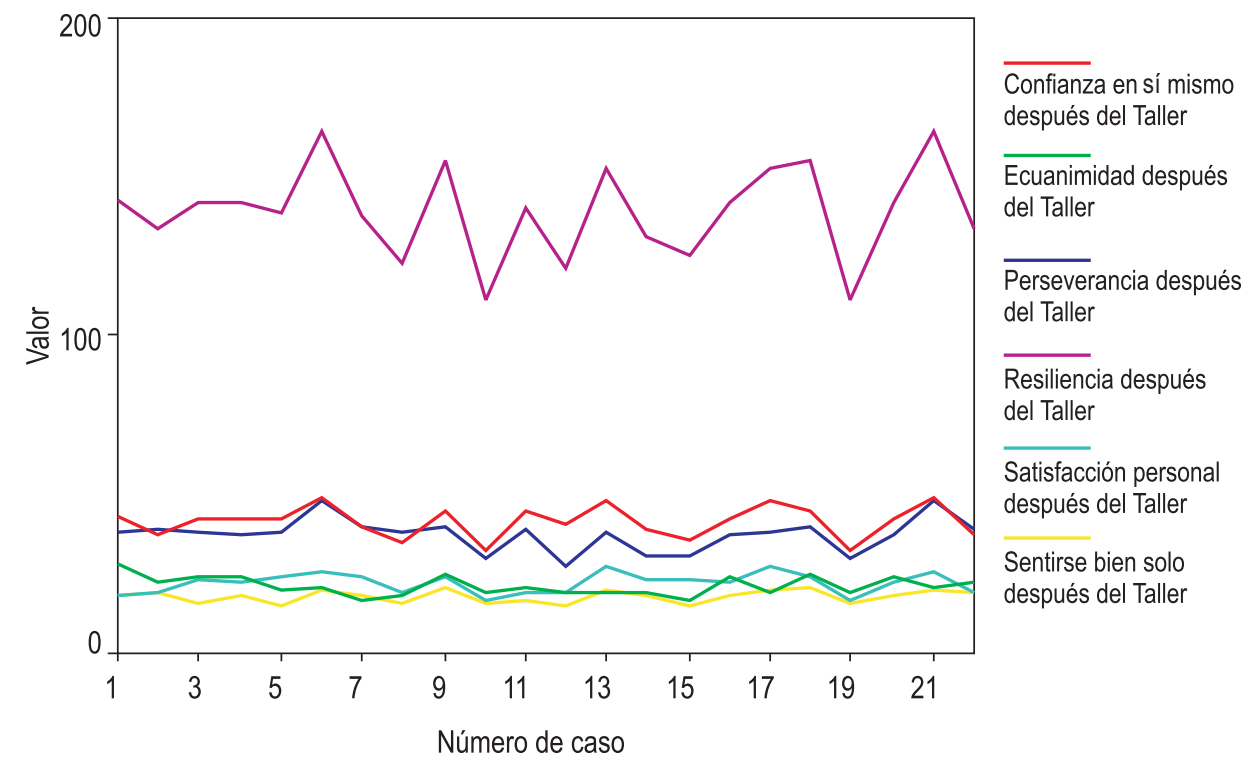

Tabla 9. Estadísticos de contraste Prueba de los rangos con signo de Wilcoxon.

\begin{tabular}{|c|c|c|c|c|c|}
\hline & $\begin{array}{c}\text { Confianza } \\
\text { en sí } \\
\text { mismo }\end{array}$ & & & & \\
\hline & $\begin{array}{c}\text { Después } \\
\text { del Taller } \\
- \\
\text { Confianza } \\
\text { en sí } \\
\text { mismo } \\
\text { antes del } \\
\text { Taller }\end{array}$ & $\begin{array}{c}\text { Ecuanimidad } \\
\text { después del } \\
\text { Taller - } \\
\text { Ecuanimidad } \\
\text { antes del } \\
\text { Taller }\end{array}$ & $\begin{array}{l}\text { Perseverancia } \\
\text { después del } \\
\text { Taller - } \\
\text { Perseverancia } \\
\text { antes del } \\
\text { Taller }\end{array}$ & $\begin{array}{c}\text { Satisfacción } \\
\text { personal } \\
\text { después } \\
\text { del Taller - } \\
\text { Satisfacción } \\
\text { personal } \\
\text { antes del } \\
\text { Taller }\end{array}$ & $\begin{array}{c}\text { Satisfacción } \\
\text { personal } \\
\text { después } \\
\text { del Taller - } \\
\text { Sentirse } \\
\text { bien solo } \\
\text { antes del } \\
\text { Taller }\end{array}$ \\
\hline Z & $-3.749^{\mathrm{a}}$ & $-2.864^{\mathrm{a}}$ & $-3.762^{\mathrm{a}}$ & $-3.432^{\mathrm{a}}$ & $-4.101^{\mathrm{a}}$ \\
\hline $\begin{array}{l}\text { Sig. } \\
\text { asintót. } \\
\text { (bilateral) }\end{array}$ & .000 & .004 & .000 & .001 & .000 \\
\hline
\end{tabular}

a. Basado en los rangos negativos.

b. Prueba de los rangos con signo de Wilcoxon 
Tabla 10. Estadísticos de contraste de la prueba de los signos 3.

\begin{tabular}{|c|c|c|c|c|c|}
\hline & $\begin{array}{c}\text { Confianza } \\
\text { en sí } \\
\text { mismo } \\
\text { después } \\
\text { del Taller } \\
- \\
\text { Confianza } \\
\text { en sí } \\
\text { mismo } \\
\text { antes del } \\
\text { Taller }\end{array}$ & $\begin{array}{c}\text { Ecuanimidad } \\
\text { después del } \\
\text { Taller - } \\
\text { Ecuanimidad } \\
\text { antes del } \\
\text { Taller }\end{array}$ & $\begin{array}{c}\text { Perseverancia } \\
\text { después del } \\
\text { Taller - } \\
\text { Perseverancia } \\
\text { antes del } \\
\text { Taller }\end{array}$ & $\begin{array}{c}\text { Satisfacción } \\
\text { personal } \\
\text { después } \\
\text { del Taller - } \\
\text { Satisfacción } \\
\text { personal } \\
\text { antes del } \\
\text { Taller }\end{array}$ & $\begin{array}{c}\text { Satisfacción } \\
\text { personal } \\
\text { después } \\
\text { del Taller - } \\
\text { Sentirse } \\
\text { bien solo } \\
\text { antes del } \\
\text { Taller }\end{array}$ \\
\hline $\begin{array}{l}\text { Sig. } \\
\text { exacta } \\
\text { (bilateral) }\end{array}$ & $.000^{\mathrm{a}}$ & $.021^{a}$ & $.000^{\mathrm{a}}$ & $.000^{\mathrm{a}}$ & $.000^{\mathrm{a}}$ \\
\hline
\end{tabular}

a. Se ha usado la distribución binomial.

b. Prueba de los signos

De las figuras 5 y 6 , y las tablas 9 y 10 se puede observar una diferencia significativa menor al 0.05 en el nivel de cada uno de los cinco componentes de la resiliencia medidos antes y después de la administración del Taller de autoaceptación personal a los participantes.

\section{CONCLUSIONES}

- $\quad$ El Taller de autovalia fundamentado en la Terapia racional emotiva de Albert Ellis es eficaz para incrementar el nivel de la conducta resiliente y de cada uno de los componentes de esta conducta en los participantes.

- $\quad$ El Taller de autovalia fundamentado en la Terapia racional emotiva de Albert Ellis es eficaz para disminuir las actitudes violentas en los participantes.

- La magnitud del cambio en ambos casos parecería depender del nivel en que se encontraban estos procesos en los participantes antes de iniciar el Taller.

\section{REFERENCIAS BIBLIOGRÁFICAS}

1. Anicama, J. Mayorga, R. Hinostroza, C. Antorini, B., Ochoa, M. y Tomas A. (1997). "Efectos de un programa cognitivo-conductual para prevenir y controlar la violencia de menores en extrema pobreza y alto riesgo". Wiñay Yachay, Revista de la Facultad de Psicología UNFV, 2(1), 71-81.

2. Alarcón, R. (1991) Metodos y diseños de investigación del comportamiento. Lima: UPCH. 
3. Aramburú; C. y Mendoza, M. (2003). "La población peruana: perspectivas y retos". Economia y sociedad. Nov. 50, 45-54.

4. Branden, N. (1994). El poder de la autoestima. Cómo potenciar este importante recurso psicológico. México: Paidós.

5. Mangiaterra, V., McGinnis, L. y Sánchez, J. (2004). Los jóvenes y el mercado laboral: ¿están preparados el uno para el otro? Simposium Internacional "Invertir en la Juventud". Santiago de Chile: Banco Mundial, octubre.

6. Mangiaterra, V., McGinnis, L. y Sánchez, J. (2005). Desarrollo del potencial de la juventud: Marco para la acción. Lectura para la video conferencia presentación de la estrategía de niñez y juventud. Lima: Banco Mundial.

7. Mardomingo, M. (2002) Psiquiatría para padres y educadores. Madrid: Narcea S.A. de Ediciones.

8. Montgomery, W. (1998). "El problema de la violencia juvenil: Análisis teorético y de programas de intervención conductual". Revista de Investigación en Psicología, $1(1)$, pp.33-52.

9. Montgomery, W. (1999). Asertividad, autoestima, y solución de conflictos interpersonales. Lima: CEA.

10. OPS (1998). Manual de identificación y promoción de la resilencia. Lima: Centro de documentación OPS/OMS-PERU.

11. Ortiz, C. (2005). Violencia juvenil. Lima: APROSEC.

12. Pratt, H. y Greydanus D. (2000). "Adolescent violence: concepts for a new millennium". Adolesc Med; 11 (1): 103-25.

13. Rutter, (1993) Resiliencia: consideraciones conceptuales. Vol. 14, No 8.

14. Salgado, A. (2005). "Inventario de resiliencia para niños: Fundamentación teórica y construcción". Cuaderno de Investigación $N^{o}$ 8. Instituto de Investigación. Escuela Profesional de Psicología. Lima: Universidad de San Martín de Porres.

15. Walsh, F. (1998). "El concepto de resiliencia familiar: crisis y desafío". En Sistemas familiares. Año 14, $\mathrm{N}^{\mathrm{o}} 1$, marzo. 


\section{ANEXOS}

\section{TALLER DE VALÍA PERSONAL Y AUTOACEPTACIÓN}

\section{OBJETIVO GENERAL}

- Posibilitar que los participantes logren una adecuada y constructiva autoaceptación y valoración personal.

\section{SESIÓN 1: RECONOCIENDO MI MODO DE VALORARME}

\section{Objetivos:}

1. El participante identificará cualidades, virtudes, limitaciones y desvirtudes de las personas a las cuales califica como valiosas y poco valiosas

2. El participante identificará las situaciones en las que él se percibió como valioso/a y poco valioso/a, así como las características determinantes.

3. Definir las características que el grupo define como cualidades de una persona valiosa.

4. El participante reconocerá el tipo de concepto que maneja sobre valía personal.

5. El participante logrará conocer por nombre, preferencias culinarias y talla del calzado a sus compañeros de grupo. 


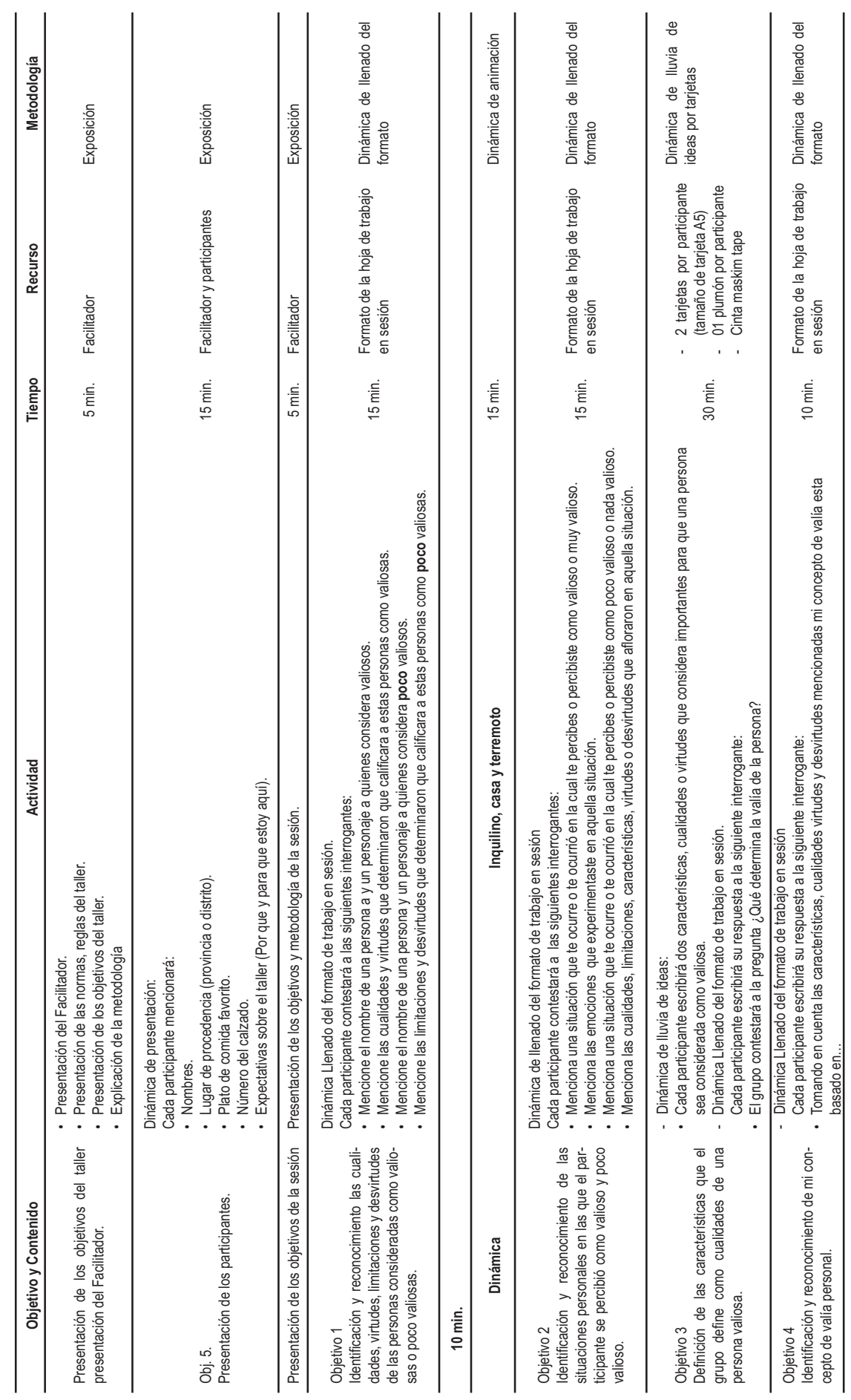




\section{SESIÓN 2: DIFERENCIANDO CONCEPTOS DE VALÍA PERSONAL}

\section{Objetivos:}

1. El participante identificará los adjetivos o comportamientos aceptados que se encuentran en su definición de valía.

2. El participante logrará diferenciar el valor intrínseco de la persona del valor condicionado a logros internos o externos o comportamientos socialmente aceptados.

3. El participante cuestionará la definición de valía basada en logros internos o externos o comportamientos socialmente aceptados.

4. El Participante reformulará el concepto de valía personal.

5. Fortalecer los vínculos entre los miembros del grupo. 


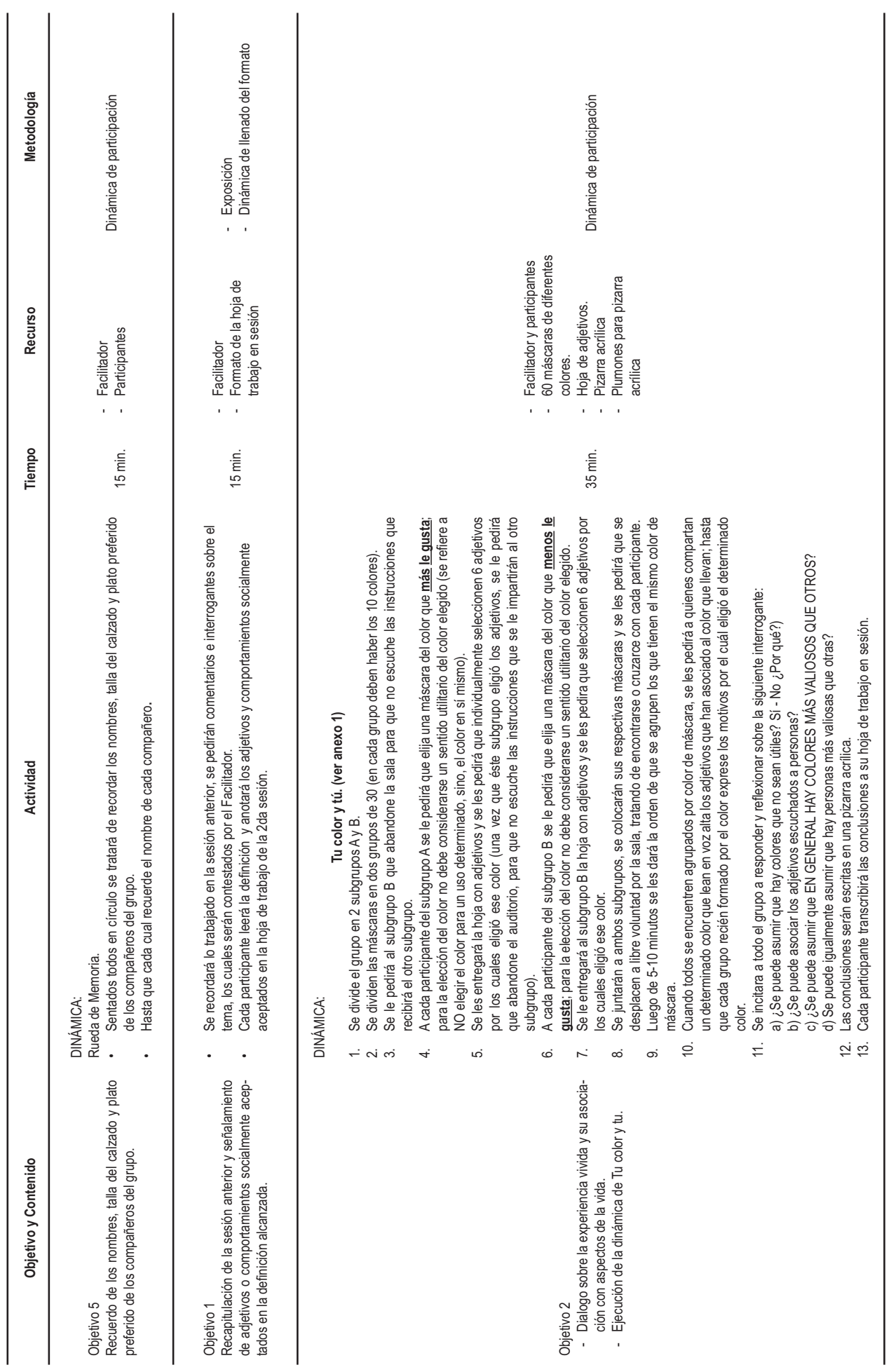




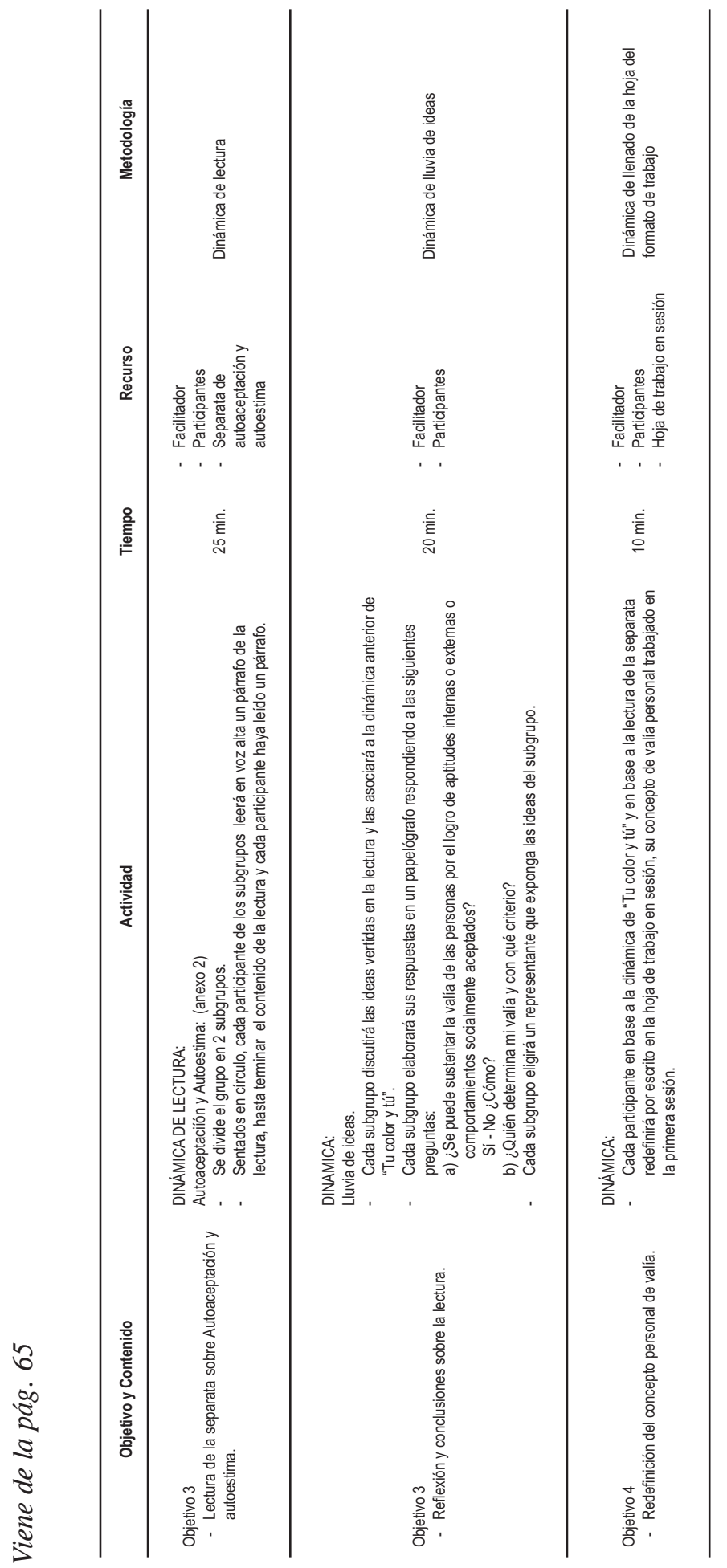




\section{SESIÓN 3: VIVIENDO EL NUEVO CONCEPTO DE VALÍA PERSONAL}

\section{Objetivos:}

1. Cada participante recordará las sesiones anteriores.

2. Cada participante aceptará y reconocerá algunos de sus rasgos positivos y negativos.

3. Cada participante expresará como percibe y aceptará como es percibido por sus compañeros.

4. Cada participante se comprometerá a trabajar en revertir una de sus desvirtudes.

5. Todo el grupo reflexionará sobre la influencia del concepto errado de valía al problema del consumo de drogas.

6. Fortalecer los vínculos entre los miembros del grupo. 


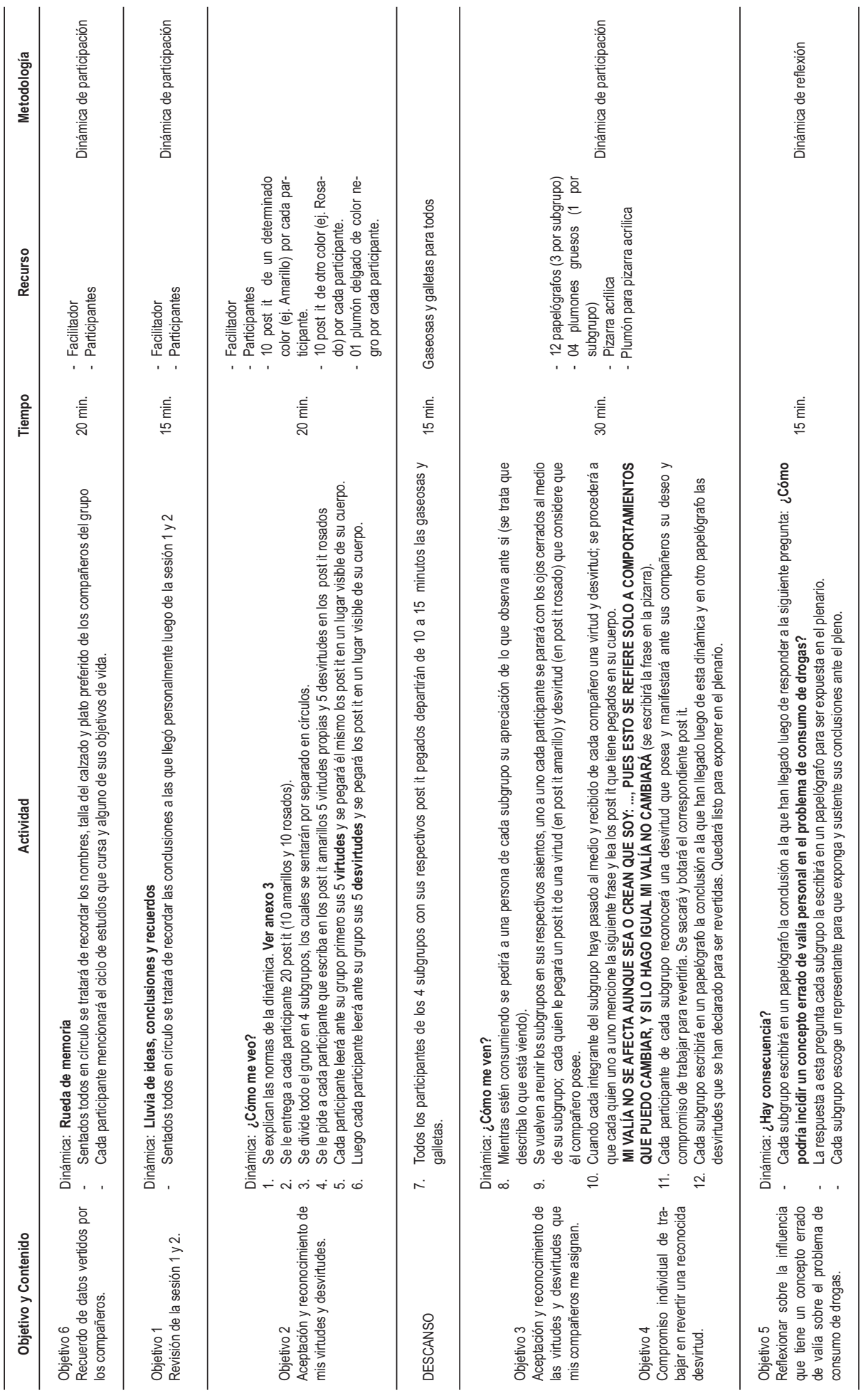


Alberto Quintana P. et al.

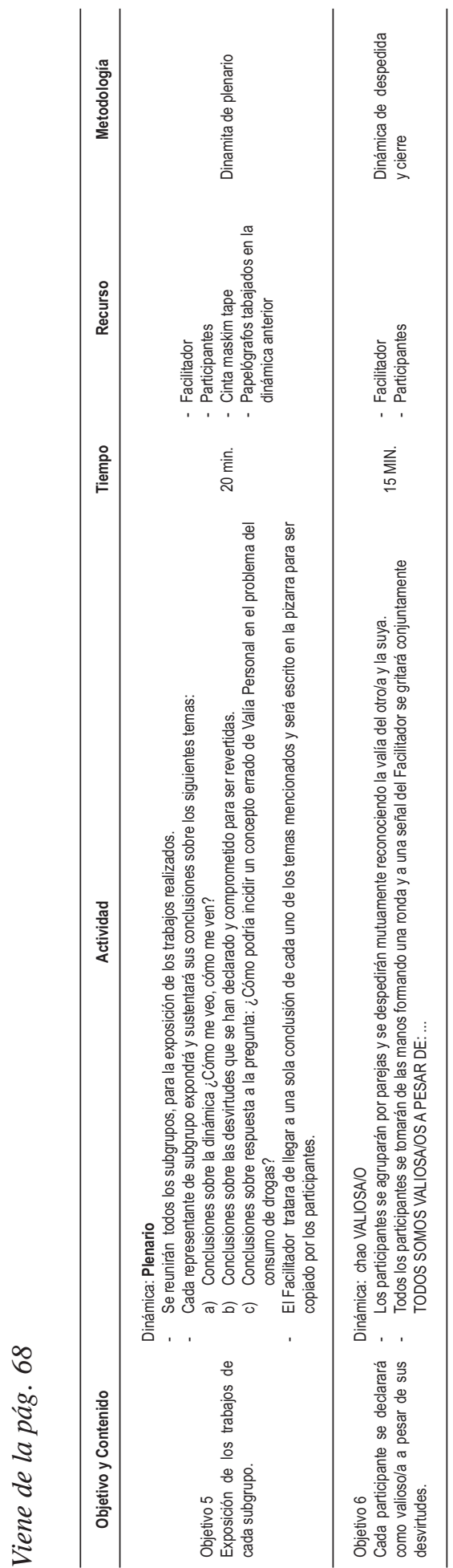

Revista de Investigación en Psicología - Vol. 10, № 2 